\title{
Desafios gerenciais do cooperativismo: fidelização versus competitividade
}

\author{
Raquel Breitenbach* \\ Janaína Balk Brandão** \\ Marcelo Nogueira ${ }^{* * * *}$
}

\begin{abstract}
Resumo
O objetivo deste trabalho foi analisar o nível de satisfação dos associados acerca dos condicionantes de competitividade da Cooperativa Agrícola X bem como compreender a percepção dos associados em relação à gestão da cooperativa, verificando suas políticas de atuação e os sistemas de fidelização do associado. A pesquisa envolveu entrevistas com uma amostra de 414 associados. Como resultados, destaca-se um bom nível de satisfação dos associados quanto aos serviços e produtos ofertados pela organização. Destacam-se como pontos com menor índice de satisfação dos associados: flexibilidade e rapidez em atender pedidos não programados, ações de preservação ao meio ambiente, reposição de perdas e serviços do departamento técnico e financeiro.
\end{abstract}

Palavras-chave: Cooperativa agrícola. Competitividade. Satisfação dos associados.

* Bacharel em Desenvolvimento Rural e Gestão Agroindustrial pela Universidade Estadual do Rio Grande do Sul. Licenciada em Desenvolvimento Rural e Gestão Agroindustrial pela Universidade Federal de Santa Maria. Mestre e doutora em Dinâmicas Econômicas e Organizacionais na Agricultura pela Universidade Federal de Santa Maria. Integrante do Núcleo de Estudos e Pesquisa em Economia Agroindustrial e do Grupo de Estudos Referentes ao Agronegócio. Professora efetiva do Instituto Federal do Rio Grande do Sul. E-mail: raquel.breitenbach@sertao.ifrs.edu.br

** Engenheira agrônoma pela Universidade Federal de Santa Maria. Mestre e doutora em Extensão Rural pela Universidade de Santa Maria. Professora adjunta III do Departamento de Educação Agrícola e Extensão Rural e do Programa de Pós-Graduação em Extensão Rural da Universidade de Santa Maria. E-mail: janainabalkbrandao@hotmail.com

*** Tecnólogo em agronegócio pelo Instituto Federal do Rio Grande do Sul, campus Sertão. Supervisor Comercial da Cooperativa Agrícola Água Santa. E-mail: engenhogrande@coasars.com.br

http://dx.doi.org/10.5335/rtee.v22i47.6833

Submissão: 24/11/2015. Aceite: 21/09/2016. 


\section{Introdução}

O cooperativismo é uma forma de associação na qual a sociedade se organiza em sistema de ajuda mútua para resolver diversos problemas relacionados ao dia a dia. De acordo com a Política Nacional de Cooperativismo, definida pela Lei no ${ }^{\circ}$.764/1971, art. $3^{\circ}$, compartilham do contrato de sociedade cooperativa as pessoas que reciprocamente se obrigam a contribuir com bens ou serviços para o exercício de uma atividade econômica, de proveito comum, sem objetivo de lucro (BRASIL, 1971).

O ano de 2012 foi escolhido pela Organização das Nações Unidas como o Ano Internacional das Cooperativas, aumentando o conhecimento da sociedade sobre essa forma de organização econômica e social, além de divulgar seu papel no desenvolvimento mundial, por meio da geração de renda e emprego. De acordo com a Aliança Cooperativa Internacional, em todo o mundo há, aproximadamente, um bilhão de pessoas que faz parte de cooperativas, dentre os ramos de atuação das cooperativas, um dos que reúne maior número de membros é o agropecuário (ALIANÇA COOPERATIVA INTERNACIONAL, 2011). No mundo, há cerca de um bilhão de pessoas que estão vinculadas uma cooperativa (ORGANIZAÇÃO DAS COOPERATIVAS DO BRASIL, 2014). No Brasil, cerca de 46 milhões de pessoas beneficiam-se de alguma forma com o cooperativismo, sendo que 11,5 milhões estão ligadas diretamente a uma das mais de 6,5 mil cooperativas que atuam em trezes ramos diferentes, envolvendo cerca de 340 mil profissionais (ORGANIZAÇÃO DAS COOPERATIVAS DO BRASIL, 2014). Em relação ao comércio exterior, as exportações brasileiras, em 2014, por intermédio das cooperativas, foram de 5,3 bilhões de reais. O número de cooperados entre 2004 e 2013 cresceu 87,9\% e o de empregos 83\% (ORGANIZAÇÃO DAS COOPERATIVAS DO BRASIL, 2014).

Mas, para Valadares ([201-?]), as evidências mostram que a sobrevivência das cooperativas no sistema econômico concorrencial capitalista requer sua integração às regras impostas pelo sistema. Essa integração provoca um conjunto de modificações na forma organizacional das cooperativas pela incessante busca da racionalidade e da eficiência econômica. Assim, o autor destaca que a ação das cooperativas diante da exigências econômicas e sociais do mundo moderno passa necessariamente pela busca de novos modelos de gestão, na tentativa de ajustar suas estruturas à realidade.

As cooperativas se vêem forçadas à evolução, assim como as demais organizações, no que diz respeito às suas atividades, à interface tecnológica, à gestão, à complexidade da estrutura organizacional, e no que diz respeito aos relacionamentos com pessoas e instituições ([201-?], p. 55).

Teoria e Evidência Econômica - Ano 22, n. 47, p. 352-368, jul./dez. 2016 
Dessa forma, observa-se que as cooperativas assumem uma atuação mais agressiva nos mercados finais, por força dos altos níveis de competitividade exigidos pelos novos mercados, deixando de lado a passividade dos modelos de gestão utilizados nas décadas anteriores (VALADARES, [201-?]).

No que diz respeito à gestão, nas cooperativas mais simples, prevalece o princípio da autogestão, na qual os próprios cooperados eleitos como dirigentes exercem a administração. Porém, nas cooperativas de maior complexidade administrativa e que atuam em mercados e atividades mais dinâmicas, a gestão passou a requerer maior grau de profissionalização e, portanto, de investimento na qualificação de seus associados-administradores e na contratação de profissionais no mercado de trabalho (VALADARES, [201-?]). Assim, destaca-se que na busca por esse novo modelo de gestão, as experiências atuais demonstram que é necessária uma reflexão inicial para que a cooperativa posicione-se em relação à sua missão, ao seu negócio, aos seus objetivos e às suas metas. E que faça tal reflexão por meio da análise da cadeia de valor de seu processo produtivo, detectando falhas e excelências e analisando as ameaças e oportunidades do ambiente externo no qual se insere. Dessa busca, já iniciada por algumas cooperativas brasileiras, alguns fatores considerados chave no sucesso já foram identificados e atualmente direcionam a ação de várias delas. O Quadro 1 apresenta sinteticamente os fatores considerados por Valadares ([201-?]).

Quadro 1 - Síntese dos fatores determinantes para o sucesso das cooperativas

\begin{tabular}{|l|l|}
\hline $\begin{array}{l}\text { Fatores-chave } \\
\text { para o sucesso }\end{array}$ & \multicolumn{1}{c|}{ Formas de operacionalização } \\
\hline $\begin{array}{l}\text { Profissionaliza- } \\
\text { ção da gestão } \\
\text { de informação gerencial e para a mudança do padrão cultural; simplificar e } \\
\text { agilizar o processo administrativo, enxugar a estrutura e aumentar a produti- } \\
\text { vidade; manter o máximo de transparência administrativa nas decisões, bem } \\
\text { como periodicamente estabelecer prioridades e metas de trabalho e avaliar a } \\
\text { situação empresarial; planos de desenvolvimento empresarial elaborados com } \\
\text { técnicas de planejamento estratégico intensificam o processo de profissionali- } \\
\text { zação da gestão e a modernização do aparato administrativo. }\end{array}$ \\
\hline $\begin{array}{l}\text { Fão antecipar dinheiro de financiamento a cooperado; não conceder crédito } \\
\text { além da capacidade de endividamento do cooperado; cobrar em dia as dívidas } \\
\text { dos associados; subscrever e integralizar novas cotas-parte de capital; excluir } \\
\text { cooperados que se beneficiam da cooperativa, mas que não mantêm fidelida- } \\
\text { de a ela. }\end{array}$ \\
$\begin{array}{l}\text { Equacionar a distribuição de lucros e benefícios ao cooperado e capitalizar a } \\
\text { empresa; criar e disseminar mecanismos de preços que valorizem a escala de } \\
\text { produção de produtos ou de serviços, a qualidade do produto ou do serviço e } \\
\text { a regularidade da oferta; também, conscientizar o cooperado de que é funda- } \\
\text { mental investir para a cooperativa crescer. }\end{array}$ \\
\hline
\end{tabular}


cont.

\begin{tabular}{|c|c|}
\hline $\begin{array}{l}\text { Tecnologia e } \\
\text { produtividade }\end{array}$ & $\begin{array}{l}\text { A modernização e o progresso tecnológico das cooperativas baseiam-se na in- } \\
\text { formação, no valor do conhecimento, na importância da qualidade e da diferen- } \\
\text { ciação de produtos e serviços no mercado concorrencial. Nesse cenário voltar } \\
\text { atenções para a pessoa que produz o produto ou serviço é o passo número } \\
\text { um. É do sucesso das unidades produtivas individuais que depende o sucesso } \\
\text { das cooperativas. A produtividade e a modernização tecnológica devem ser } \\
\text { buscadas em toda a cadeia de valor. Caberá às cooperativas liderar a criação } \\
\text { e a implantação de mecanismos que incentivem a especialização dos coopera- } \\
\text { dos, como o pagamento diferenciado que força a melhoria dos índices técnicos } \\
\text { de produção de serviços médicos e o nível de qualidade desse serviço. }\end{array}$ \\
\hline $\begin{array}{l}\text { Organização } \\
\text { empresarial }\end{array}$ & $\begin{array}{l}\text { Geração de um quadro de associados mais compromissado com as ativida- } \\
\text { des e decisões da cooperativa. Garantir o comprometimento dos produtores } \\
\text { com as decisões da direção da cooperativa e, consequentemente, propiciar } \\
\text { um maior nível de investimentos dos cooperados. Em decorrência, as coope- } \\
\text { rativas terão condições de atuar de forma mais agressiva nos mercados de } \\
\text { produtos e serviços nos quais têm participação. } \\
\text { Com a crescente profissionalização de seu quadro diretivo e o maior compro- } \\
\text { metimento do seu quadro social, por meio da fidelidade, acompanhamento e } \\
\text { monitoramento das decisões da direção, há a evolução de um modelo de- } \\
\text { fensivo de organização para um modelo que possibilite assumir uma atitude } \\
\text { ofensiva com relação aos mercados, profissionalizando suas atividades e au- } \\
\text { mentando o comprometimento de seus cooperados com os destinos traçados } \\
\text { para a empresa. }\end{array}$ \\
\hline $\begin{array}{l}\text { Enfoque no } \\
\text { cliente }\end{array}$ & $\begin{array}{l}\text { A pesquisa de mercado, o marketing e a publicidade passam a ser funda- } \\
\text { mentais para a empresa moderna e cabe à cooperativa conscientizar todos } \\
\text { os associados para tal exigência. As expectativas do consumidor quanto aos } \\
\text { produtos e serviços são muitas e a tendência é que sejam cada vez mais acu- } \\
\text { radas. Com vistas a garantir sua produtividade e competitividade no mercado, } \\
\text { as cooperativas precisam administrar o vasto deserto tecnológico que as ca- } \\
\text { racteriza - com relação ao padrão tecnológico do cooperado, aos modelos de } \\
\text { gestão e às estratégias de integração regional - e desempenhar papéis que } \\
\text { lhes permitam especializar-se e alcançar níveis de competitividade. }\end{array}$ \\
\hline
\end{tabular}

Fonte: elaborado pelos autores com base em Valadares ([201-?]).

A busca pela eficiência na gestão pode ser verificada em evidências empíricas. Exemplos disso são as iniciativas premiadas pela Organização das Cooperativas Brasileiras, que, em 2014, premiou três cooperativas que apresentam iniciativas inovadoras de gestão, incluindo a categoria Fidelização. Esse ranking visa premiar práticas e projetos elaborados com a meta de aproximar o cooperado e aumentar sua participação no cotidiano da cooperativa, que lhe permite contar com um quadro social fidelizado, comprometido com o crescimento da instituição (ORGANIZAÇÃO DAS COOPERATIVAS BRASILEIRAS, 2014). Das três cooperativas, duas eram de produção, o primeiro lugar ficou com a COOPATOS, do município Patos de Minas (MG), devido à Semana Coopatos, e o terceiro lugar com a C.VALE, de Palotina (PR). 
Os dirigentes da COOPATOS, criada em 1957, explicam que o projeto surgiu com a constatação de que era necessário redirecionar as ações para aumentar a competitividade na oferta de produtos e serviços aos cooperados. Para que houvesse o sucesso do projeto, deveria haver a mudança de aspectos culturais, pois a cooperativa estava levando à região um tipo de negócio inovador, que poderia encontrar certa resistência da comunidade (GLOBO RURAL, 2014).

Desde a primeira edição, a Semana Coopatos revelou-se um evento de grande importância não só para os seus cooperados como para todos da região de abrangência da cooperativa. Em sua programação, havia atividades como palestras técnicas, exposição de fornecedores, torneios de produtividade, leilões de animais, shows e várias ações de âmbito cooperativista. O evento é realizado em parceria com expositores, patrocinadores e apoiadores institucionais. Em 2014, a cooperativa investiu $R \$ 150$ mil em recursos próprios e contou com aporte de $R \$ 586,5$ mil de parceiros do projeto (COOPATOS, 2015). Os dirigentes observam que a diversidade de eventos resultou na maior participação de cooperados, que inicialmente eram 225 e passaram a 1.800 .

O projeto Cooperativismo do Futuro, desenvolvido pela C.VALE, de Palotina $(\mathrm{PR})$, foi o terceiro colocado na categoria fidelização. O objetivo do projeto é estreitar os laços com as novas gerações de associados e suas famílias. Os dirigentes da C.Vale destacam que a campanha despertou os jovens para a importância da atuação da cooperativa na estruturação dos negócios da família. Segundo os dirigentes, em pouco tempo, os jovens perceberam o papel da C.Vale, quando a cooperativa fornece apoio técnico, facilita o acesso ao crédito e, assim, melhora as condições de compra de insumos e de escoamento da produção (C.VALE, 2014).

Pondera-se que a existência e manutenção das cooperativas dependem do seu vínculo com os associados, que são os responsáveis pela gestão dos negócios. Portanto, a participação e a atuação direta fortalecem a cooperativa, já que determinam os rumos a serem seguidos pelo negócio (PIVOTO, 2013). Nesse contexto, destaca-se que com a fidelidade dos associados é possível o planejamento sustentado e o crescimento da cooperativa, já que associados comprometidos, participativos e fiéis são fatores fundamentais para a segurança dos negócios da cooperativa, interligados, é claro, a uma gestão eficiente.

Pivoto (2013) considera que o cooperativismo agropecuário no Rio Grande do Sul passa por um período de reestruturação e que muitas cooperativas agropecuárias passam por crises financeiras, algumas até estão em processo de liquidação. $\mathrm{O}$ autor alerta, ainda, que o cenário atual exige uma análise do cooperativismo agropecuário no estado, buscando identificar e resolver os problemas. 
Nesse contexto, o intuito deste trabalho é analisar o nível de satisfação dos associados quanto aos condicionantes de competitividade de uma importante cooperativa agrícola do Norte do estado do Rio Grande do Sul, compreendendo a percepção dos associados em relação à gestão da cooperativa, verificando suas políticas de atuação e os sistemas de fidelização do associado.

\section{Material e métodos}

Acooperativa agrícola estudada, doravante denominada Cooperativa Agrícola X está localizada na cidade de Água Santa, no Rio Grande do Sul, com um quadro de associados composto por $77 \%$ de agricultores familiares. A Cooperativa Agrícola X atende seus associados em filiais distribuídas em boa parte da Região Norte do Rio Grande do Sul, desse modo os agricultores de outros municípios também podem se beneficiar com os serviços prestados. Cada filial mantém uma equipe com profissionais da área técnica para atender e colaborar com os associados para que o associado possa produzir melhor, com mais eficiência e de maneira correta.

A Tabela 1 mostra onde estão localizadas as filiais e o número de associados que participaram da pesquisa, que contemplou todos os municípios da região de atuação da Cooperativa Agrícola X.

Tabela 1 - Localização dos agricultores participantes da pesquisa

\begin{tabular}{l|c}
\hline \multicolumn{1}{c|}{ Município } & Entrevistados (\%) \\
\hline Santa Cecília & $7,73 \%$ \\
Mato Castelhano & $22,71 \%$ \\
Tapejara & $1,45 \%$ \\
Gentil & $1,93 \%$ \\
Água Santa & $32,61 \%$ \\
Ciríaco & $13,29 \%$ \\
Coxilha & $0,96 \%$ \\
Vila Lângaro & $13,04 \%$ \\
Lagoa Vermelha & $0,97 \%$ \\
Caseiros & $3,86 \%$ \\
David Canabarro & $1,45 \%$ \\
Total & $100,00 \%$ \\
\hline
\end{tabular}

Fonte: elaboração dos autores com base da pesquisa. 
Portanto, para identificar o nível de satisfação dos associados quanto aos diversos fatores envolvendo os serviços prestados pela cooperativa, este estudo de caso levou em consideração os seguintes aspectos: preços de produtos comercializados pelos concorrentes, preços dos produtos agrícolas comercializados, tecnologia dos produtos, condições de pagamento, pós-venda, parceria associado e cooperativa, prazo de entrega, localização, qualidade do produto, imagem da cooperativa, capacidade dos funcionários, capacitações para associados, flexibilidade dos pedidos, preservação ambiental, responsabilidade social, ofertas e ações nos produtos, reposição de perdas, comunicação, mix de produtos, atendimento no balcão e vendas, assistência técnica, atendimento financeiro, informação na aquisição de produtos, participação nas decisões e ações.

Para o levantamento dos dados empíricos foi utilizado um instrumento de coleta de dados, na forma de questionário, aplicado em uma amostra de 414 associados, sobre uma população de 2.187 sócios da cooperativa em estudo. Para a definição da amostra foi utilizada a fórmula:

$$
n=\frac{N \cdot Z^{2} \cdot p \cdot(1-p)}{Z^{2} \cdot p \cdot(1-p)+e^{2} \cdot(N-1)}
$$

O valor definido como erro amostral foi de 5\%, com nível de confiança de $95 \%$. A amostra foi aleatória, já que os primeiros associados que foram até a sede da cooperativa foram respondendo o questionário. Para a amostra foi considerada a representatividade das regiões de atuação da cooperativa, ou seja, todas as filiais tiveram associados respondentes de forma proporcional.

O questionário fechado aplicado contemplava questões de múltipla escolha, cujas respostas eram definidas em alternativas previamente estabelecidas. No caso específico da pesquisa, as alternativas corresponderam às seguintes opções: 1 - totalmente insatisfeito; 2 - Insatisfeito; 3 - Razoavelmente satisfeito; 4 - Satisfeito; 5 - Totalmente satisfeito.

Após a aplicação dos questionários, os dados foram tabulados em planilha Excel e tratados estatisticamente pelo programa estatístico SPSS (Statistical Package for the Social Sciences). As análises realizadas foram univariada e bivariada. 


\section{Resultados e discussão}

\subsection{Políticas de comercialização da cooperativa}

Verifica-se que existem algumas políticas adotadas pela Cooperativa Agrícola $\mathrm{X}$ cujo intuito é beneficiar (fidelizar) o associado. Nesse sentido, cita-se a devolução de parte das sobras líquidas de cada ano, proporcional ao seu movimento de compra e venda da safra, sendo que o valor lhe é creditado na forma de cota capital.

Outra forma relevante de atuação refere-se à diferenciação de preço pago ao associado, pois a cooperativa oferece preço superior ao praticado no mercado, incentivando o agricultor a entregar seu produto para a Cooperativa Agrícola X. Constatou-se também a existência de contratos de garantia de preço, tratando de preço futuro, garantindo ao associado o valor no momento da colheita. Assim, por meio desse contrato, o agricultor fica assegurado e a cooperativa repassa o serviço para corretoras ou mesmo para esmagadoras de grãos.

Por outro lado, existe o acompanhamento técnico fornecido pela cooperativa aos estabelecimentos de seus associados, como o planejamento de projetos de plantio (investimentos e custeio de lavouras), realizado por uma equipe de técnicos especializados em atender a todas as demandas dos associados e clientes.

\subsection{Análise de satisfação dos associados da Cooperativa Agrícola X}

Esta seção apresenta os resultados do nível de satisfação dos associados da Cooperativa Agrícola X. Para tanto, é dividida em duas etapas: na primeira, apresenta-se a análise univariada dos resultados, ou seja, discute-se cada um dos itens considerados no levantamento da satisfação, apresentando o percentual de associados totalmente insatisfeitos, insatisfeitos, mediamente satisfeitos, satisfeitos e totalmente satisfeitos. Além disso, discute-se alguns fatores que podem ser os responsáveis por essa satisfação, ou não, dos associados. Na segunda parte, são apresentadas as análises bivariadas realizadas com base no Programa SPSS, quando foi feito o cruzamento de localização dos associados com todas as varáveis no intuito de identificar se havia diferença no nível de satisfação dos associados em diferentes filiais. 


\subsubsection{Análise geral da satisfação dos associados da Cooperativa Agrícola $\mathrm{X}$ em relação a critérios de vantagem competitiva}

As oito condicionantes ponderadas demonstram o percentual de associados em cada um dos níveis de satisfação pré-estabelecidos para a pesquisa nos oito primeiros condicionantes analisados (Tabela 2). Observa-se que o nível de satisfação dos associados, em sua maioria, ficou de medianamente satisfeito a totalmente satisfeito. Porém, em duas questões, obteve-se a opção Insatisfação apontada por alguns associados, esses são aspectos que precisam ser revistos e melhorados (Tecnologia dos produtos comercializados e Condições de pagamento).

Tabela 2 - Análise de satisfação dos associados da Cooperativa Agrícola X, parte 1

\begin{tabular}{l|c|c|c|c|c}
\hline \multicolumn{1}{c|}{ Nível de satisfação } & $\begin{array}{c}\text { Totalmente } \\
\text { insatisfeito }\end{array}$ & Insatisfeito & $\begin{array}{c}\text { Medianamente } \\
\text { satisfeito }\end{array}$ & Satisfeito & $\begin{array}{c}\text { Totalmente } \\
\text { satisfeito }\end{array}$ \\
\hline $\begin{array}{l}\text { Produtos comercializados pela cooperati- } \\
\text { va (em reais) }\end{array}$ & 0 & 0 & 18,4 & 62,3 & 19,3 \\
$\begin{array}{l}\text { e Produtos comercializados para a coo- } \\
\text { perativa (em reais) }\end{array}$ & 0 & 0 & 20,8 & 58,9 & 20,3 \\
$\begin{array}{l}\text { Tecnologia dos produtos comercializados } \\
\text { pela cooperativa (em reais) }\end{array}$ & 0 & 1 & 7,7 & 72,9 & 18,4 \\
$\begin{array}{l}\text { Condições de pagamento na compra de } \\
\text { produtos }\end{array}$ & 0,2 & 1 & 7,2 & 54,8 & 36,2 \\
$\begin{array}{l}\text { Condições de pagamento da venda da } \\
\text { produção }\end{array}$ & 0 & 0 & 12,3 & 50,2 & 37 \\
Assistência pós-venda & 0 & 0 & 16,4 & 58 & 25,4 \\
Parceria associado & 0 & 0 & 10,1 & 49,8 & 40,1 \\
Prazo de entrega dos produtos adquiridos & 0,2 & 0,2 & 13,8 & 46,9 & 38,9 \\
\hline
\end{tabular}

Fonte: elaboração dos autores com base da pesquisa.

A Tabela 3 apresenta os principais fatores correlacionados que ocasionam a satisfação e, principalmente, a insatisfação dos condicionantes analisados a fim de identificar a realidade analisada sob cada aspecto competitivo contemplado na pesquisa. 
Tabela 3 - Grupo 1 de condicionantes de competitividade da Cooperativa Agrícola X, opção Satisfação

Condicionantes de competitividade

Os preços dos produtos comercializados pela Cooperativa Agrícola $X$ comparados com os da concorrência

Os preços dos produtos agrícolas comercializados para a Cooperativa Agrícola X comparados com a concorrência

Tecnologia dos produtos (embalagem, aparência) comercializados para a Cooperativa Agrícola $X$ comparados com a concorrência

Condições de pagamento (parcelamento, prazos, etc.) na compra de produtos

Condições de pagamento (parcelamento, prazos, etc.) na comercialização da produção

A frequência e a qualidade da assistência pós-venda

Parceria entre associado e a cooperativa

Prazo de entrega dos produtos adquiridos na cooperativa
Considerações acerca da satisfação dos associados

A questão acerca dos preços foi apontada como de satisfação razoável por $18,4 \%$ dos associados, o que pode ser explicado pelo fato de a área de atuação da cooperativa ter várias empresas ofertantes de insumos. Concorrentes entram nessa área com muita agressividade para buscar o mercado que tem potencial. Dessa forma, nem sempre é possível ser líder em preços baixos.

A cooperativa trabalha com preços diferenciados para associados, principalmente os que têm carta de aptidão ao Pronaf. Dessa forma, o nível de satisfação apresentado na pesquisa foi de $20,8 \%$ de associados razoavelmente satisfeitos, $58,9 \%$ satisfeitos e $20,3 \%$ totalmente satisfeitos.

A cooperativa mantém boa tecnologia nos produtos oferecidos a seus associados, tanto que $72,9 \%$ mostraram-se satisfeitos. Por outro lado, 7,7\% consideraram que estão razoavelmente satisfeitos, explicado pelo fato de algumas unidades da Cooperativa Agrícola $X$ ter depósitos com espaço limitado o que, muitas vezes, compromete a aparência do produto.

Devido a reformulações no setor financeiro da cooperativa, que ficou mais rigoroso, as exigências e os prazos são analisados caso a caso e pode ser por isso que muitos associados estão insatisfeitos ou razoavelmente satisfeitos. Porém, esse procedimento foi adotado para diminuir a inadimplência na cooperativa, e já apresenta bons resultados.

Ainda existe insatisfação de alguns associados quanto a esse fator, que pode ser explicado em alguns casos, pois o pagamento leva de dez a quinze dias para ser efetuado, no caso do milho e do trigo. Desse modo, sempre poderá haver associados não totalmente satisfeitos, que desejam o pagamento à vista.

A análise apontou que o serviço pós-venda está passando por problemas, apenas $25 \%$ dos associados estão totalmente satisfeitos. Isso mostra que não está se fazendo o acompanhamento após a conclusão dos negócios. Esse aspecto está sendo trabalhado pela equipe técnica da cooperativa, para que possa ser corrigido e o associado tenha assistência personalizada e programada.

A parceria associado e cooperativa cresce anualmente e o acumulado de totalmente satisfeitos ou satisfeitos demonstra que $90 \%$ dos associados estão satisfeitos com a forma de trabalho da cooperativa.

O prazo de entrega é um fator que não depende somente da cooperativa, já que muitas vezes depende de terceiros para a entrega dos produtos que a cooperativa irá repassar para os associados. Essa dificuldade de controle com outras empresas faz com que exista um índice de insatisfação dos sócios, por haver demora em alguns casos.

Fonte: elaboração dos autores com base da pesquisa.

Na Tabela 4, apresenta-se um segundo conjunto de condicionantes de competitividade, também analisados sob o aspecto da satisfação dos associados. As questões que tiveram destaque devido ao índice de insatisfação explicam-se especialmente 
devido à distância das unidades de atendimento da sede da cooperativa ou por fatores como mais concorrentes diretos, que fazem com que o associado tenha mais oportunidades de negociação. Dessa forma, percebe-se que o concorrente pode ter alguma vantagem competitiva.

Tabela 4 - Análise de satisfação dos associados da Cooperativa Agrícola X, parte 2

\begin{tabular}{l|c|c|c|c|c}
\hline \multicolumn{1}{c|}{ Nível de satisfação } & $\begin{array}{c}\text { Totalmente } \\
\text { insatisfeito }\end{array}$ & Insatisfeito & $\begin{array}{c}\text { Medianamente } \\
\text { satisfeito }\end{array}$ & Satisfeito & $\begin{array}{c}\text { Totalmente } \\
\text { satisfeito }\end{array}$ \\
\hline Localização Cooperativa Agrícola X & 0,5 & 0,7 & 12,6 & 39,6 & 45,7 \\
Garantia do produto & 0 & 0 & 6,5 & 56,3 & 37,2 \\
Imagem da Cooperativa Agrícola X & 0 & 0 & 13,5 & 51,9 & 34,3 \\
Capacitação dos funcionários & 0 & 0 & 5,8 & 72,9 & 21,3 \\
Capacitações para associados & 0 & 0 & 16,9 & 69,6 & 13,5 \\
Pedidos não programados & 0 & 0 & 31,4 & 53,6 & 14,7 \\
Preservação ambiental & 0 & 0,2 & 29,7 & 61,6 & 7,5 \\
Responsabilidade social & 0 & 0,2 & 11,8 & 59,4 & 27,8 \\
\hline
\end{tabular}

Fonte: elaboração dos autores com base da pesquisa.

A seguir, na Tabela 5, são descritos os itens contemplados pela Tabela 4 no que se refere aos motivadores de satisfação quanto aos condicionantes analisados.

Tabela 5 - Grupo 2 de condicionantes de competitividade da Cooperativa Agrícola Xe considerações acerca da satisfação dos associados

\begin{tabular}{l|l}
\hline \multicolumn{1}{c|}{$\begin{array}{c}\text { Condicionantes de } \\
\text { competitividade }\end{array}$} & \multicolumn{1}{c}{ Considerações acerca da satisfação dos associados } \\
\hline Localização da cooperativa & $\begin{array}{l}\text { A cooperativa buscou fixar-se em locais estratégicos, em que não houvesse } \\
\text { tanta concorrência, e acabou ficando distante de alguns associados, depen- } \\
\text { dendo da região em que eles residem. Destaca-se ainda que alguns asso- } \\
\text { ciados são de localidades e municípios onde já existem outras cooperativas } \\
\text { estabelecidas e a Cooperativa Agrícola X procura não se estabelecer nessas } \\
\text { áreas, o que pode não ser bem compreendido pelos associados. }\end{array}$ \\
\hline $\begin{array}{l}\text { Garantia do produto entregue } \\
\text { conforme as especificações } \\
\text { (padrão/ qualidade) }\end{array}$ & $\begin{array}{l}\text { Esse item teve alto índice de satisfação, demonstrando que a cooperativa } \\
\text { consegue cumprir com o estabelecido. }\end{array}$ \\
\hline $\begin{array}{l}\text { A marca ou nome da coope- } \\
\text { rativa (imagem) }\end{array}$ & $\begin{array}{l}\text { A marca da Cooperativa Agrícola X ainda precisa ser fortalecida, já que a } \\
\text { pesquisa mostrou que } 51,9 \% \text { dos associados estão satisfeitos e 13,5\% ra- } \\
\text { zoavelmente satisfeitos. Isso demonstra que até então não houve um traba- } \\
\text { Iho que fortalecesse a marca ou o nome. }\end{array}$ \\
\hline $\begin{array}{l}\text { A capacitação dos seus fun- } \\
\text { cionários }\end{array}$ & $\begin{array}{l}\text { Este índice aponta um nível bastante elevado de satisfeitos, o que mostra } \\
\text { que a cooperativa esforça-se para capacitar seus funcionários, incentivando } \\
\text { a participação em cursos de graduações e pós-graduação. }\end{array}$ \\
\hline
\end{tabular}


cont.

\begin{tabular}{l|l}
\hline $\begin{array}{l}\text { As capacitações ofertadas } \\
\text { aos associados }\end{array}$ & $\begin{array}{l}\text { A cooperativa proporciona aos sócios muitos cursos de formação e trabalha } \\
\text { o lado humano e a relação com os associados, programando palestras entre } \\
\text { os casais nas comunidades. Esse fator está sendo trabalhado com mais in- } \\
\text { tensidade nos últimos anos. }\end{array}$ \\
\hline $\begin{array}{l}\text { Resposta rápida a pedidos } \\
\text { não programados (flexibilida- } \\
\text { de/rapidez) }\end{array}$ & $\begin{array}{l}\text { Este quesito apresenta o índice de satisfação. Segundo informações obtidas } \\
\text { na cooperativa, alguns associados deixam para a última hora a tomada de } \\
\text { decisão, o que é ruim para cooperativa, que nem sempre consegue atender } \\
\text { às solicitações com rapidez. A cooperativa trabalha com vendas antecipadas } \\
\text { e estoque mínimo, isso dificulta o atendimento de pedidos de última hora. }\end{array}$ \\
\hline $\begin{array}{l}\text { Ações de preservação am- } \\
\text { biental }\end{array}$ & $\begin{array}{l}\text { A cooperativa não trabalhava este quesito, embora, no último ano, tenha ade- } \\
\text { rido a várias campanhas e, por isso, muitos associados ainda não se sentem } \\
\text { satisfeitos, talvez por não ter acesso às campanhas realizadas. }\end{array}$ \\
\hline $\begin{array}{l}\text { Responsabilidade social da } \\
\text { cooperativa }\end{array}$ & $\begin{array}{l}\text { Na pergunta sobre a responsabilidade social não foi possivel identificar as } \\
\text { causas de insatisfação, é necessário aprofundar a pesquisa para identificar } \\
\text { com exatidão os motivos. }\end{array}$ \\
\hline
\end{tabular}

Fonte: elaboração dos autores com base da pesquisa.

Na Tabela 6 evidencia-se a insatisfação em relação a alguns pontos, mostrando que a cooperativa precisa tomar algumas medidas para ajustar fatores, como a reposição de perdas, o mix de produtos, o atendimento no balcão e a participação nas decisões. Mas a opção Satisfeito, que prevaleceu em todas as questões, deixou evidente que a organização atende às expectativas dos agricultores de um modo geral, embora ajustes tenham de ser feitos em alguns aspectos para que a cooperativa tenha ainda mais participação no mercado em que atua.

Tabela 6 - Análise de satisfação dos associados da Cooperativa Agrícola X, parte 3

\begin{tabular}{l|r|r|r|r|r}
\hline \multicolumn{1}{c|}{ Nível de satisfação } & $\begin{array}{c}\text { Totalmente } \\
\text { insatisfeito }\end{array}$ & Insatisfeito & $\begin{array}{c}\text { Medianamente } \\
\text { satisfeito }\end{array}$ & Satisfeito & $\begin{array}{c}\text { Totalmente } \\
\text { satisfeito }\end{array}$ \\
\hline Promoções & 0 & 0 & 14,7 & 66,7 & 18,1 \\
Reposição de perdas & 0 & 1,7 & 18,1 & 61,1 & 18,6 \\
Facilidade de comunicação & 0 & 0,7 & 21,3 & 61,8 & 15 \\
Mix de produtos & 0 & 2,2 & 16,7 & 48,1 & 32,1 \\
Atendimento do balcão/vendas & 0 & 0,5 & 6,5 & 53,4 & 39,1 \\
Assistência técnica & 0 & 0 & 8 & 65,5 & 26,3 \\
Atendimento setor financeiro & 0 & 0 & 27,1 & 53,4 & 19,6 \\
Informação produtos adquiridos & 0 & 0 & 7,5 & 68,8 & 23,7 \\
Participação nas decisões & 0,2 & 1,2 & 33,8 & 50,5 & 14,3 \\
\hline
\end{tabular}

Fonte: elaboração dos autores com base da pesquisa.

A seguir, na Tabela 7, são explanadas as questões relativas aos condicionantes de competitividade da Cooperativa Agrícola X e as devidas considerações acerca da satisfação dos associados. 
Tabela 7 - Grupo 1 de condicionantes de competitividade da Cooperativa Agrícola X e considerações acerca da satisfação dos associados

\begin{tabular}{|c|c|}
\hline $\begin{array}{l}\text { Condicionantes de } \\
\text { competitividade }\end{array}$ & Considerações acerca da satisfação dos associados \\
\hline $\begin{array}{l}\text { Oferta de ações promocionais nas } \\
\text { diversas categorias de produtos }\end{array}$ & $\begin{array}{l}\text { Observou-se que } 14 \% \text { dos associados não estão satisfeitos com as promo- } \\
\text { ções realizadas pela organização, ou seja, a cooperativa não está competi- } \\
\text { tiva no que se refere a esse item. }\end{array}$ \\
\hline $\begin{array}{l}\text { Reposição de perdas (produtos } \\
\text { estragados, avariados, irregula- } \\
\text { res) }\end{array}$ & $\begin{array}{l}\text { A questão mostrou percentual de satisfação bem elevado, mas ainda apresen- } \\
\text { ta índice de insatisfeitos e de medianamente satisfeitos. O mercado em que a } \\
\text { cooperativa atua tem muitos fornecedores e, por isso, fica dependente de ter- } \\
\text { ceiros, assim nem sempre é possível fazer da forma que o associado gostaria. }\end{array}$ \\
\hline $\begin{array}{l}\text { Facilidade de comunicação com } \\
\text { a cooperativa }\end{array}$ & $\begin{array}{l}\text { O que se destacou na pesquisa é a difícil comunicação com a equipe técni- } \\
\text { ca, pois muitos associados reclamam dos telefones que nunca estão dispo- } \\
\text { níveis. A cooperativa está procurando melhorar as linhas telefônicas. }\end{array}$ \\
\hline Mix de produtos & $\begin{array}{l}\text { O que pode justificar a insatisfação de muitos nesse item é o fato de prefe- } \\
\text { rirem marcas comerciais ou produtos com os quais a cooperativa não tra- } \\
\text { balha. Por outro lado, a cooperativa busca satisfazer os clientes com linhas } \\
\text { destaque no mercado. }\end{array}$ \\
\hline Atendimento do balcão/vendas & $\begin{array}{l}\text { O atendimento ao balcão varia com base nas unidades. Muitas vezes, o } \\
\text { associado quer mais tempo e algumas filiais dispõem de pouco pessoal, que } \\
\text { precisa ser ágil, o que pode deixar o associado insatisfeito. }\end{array}$ \\
\hline Assistência técnica & $\begin{array}{l}\text { A Cooperativa Agrícola } X \text { investe em assistência técnica personalizada } \\
\text { para os associados, que mostra um resultado satisfatório, já que a pesquisa } \\
\text { apontou } 65,5 \% \text { dos associados como satisfeitos. A cooperativa continua in- } \\
\text { vestindo nesse item, considerando as possibilidades de melhoria. }\end{array}$ \\
\hline Atendimento do setor financeiro & $\begin{array}{l}\text { O setor financeiro apontou um índice médio de satisfação devido a muitos } \\
\text { fatores difíceis de explicar sem um aprofundamento de pesquisa. }\end{array}$ \\
\hline $\begin{array}{l}\text { Disponibilidade de informação } \\
\text { sobre os produtos adquiridos }\end{array}$ & $\begin{array}{l}\text { As informações acerca dos produtos da cooperativa são disponibilizadas de } \\
\text { modo que o associado tenha amplo conhecimento sobre o que está adquirindo. }\end{array}$ \\
\hline $\begin{array}{l}\text { Participação nas decisões e } \\
\text { ações da Cooperativa Agrícola X }\end{array}$ & $\begin{array}{l}\text { Nem todas as decisões na cooperativa podem passar por todos do quadro de as- } \\
\text { sociados, por haver a necessidade de agilidade, com isso cria-se a insatisfação. } \\
\text { Porém, a cooperativa sempre toma as decisões com os integrantes do conselho } \\
\text { fiscal e da direção reunidos, que são os representantes imediatos nas decisões. }\end{array}$ \\
\hline
\end{tabular}

Fonte: elaboração dos autores com base da pesquisa.

\subsubsection{Análise da satisfação dos associados da Cooperativa Agrícola $\mathrm{X}$ em relação às particularidades de localização}

A análise bivariada realizada contemplou o cruzamento de localização dos associados com todas as variáveis analisadas. Essa análise não demonstrou haver, necessariamente, correlação entre as variáveis. Entretanto, dá-se destaque para os resultados das análises que apresentaram maiores diferenças entre as localizações/unidades da Cooperativa Agrícola X.

Destaca-se que Mato Castelhano apresentou um percentual de associados totalmente insatisfeito ou pouco satisfeitos com a localização da cooperativa. Isso 
porque as unidades ficam distante $13 \mathrm{~km}$ do município. Os associados apontam a necessidade de ter uma unidade mais próxima, para que possam ser atendidos de melhor forma. Em Vila Lângaro, a pesquisa apontou insatisfação também, já que a unidade mais próxima a esse município está localizada a uma distância mínima de aproximadamente de $12 \mathrm{~km}$.

No que se refere aos preços dos produtos agrícolas comercializados pela Cooperativa Agrícola X para os agricultores, o município de Caseiros ficou em destaque com um percentual elevado de media satisfação, com $43,8 \%$ dos entrevistados. A explicação para a insatisfação é pelo fato de a concorrência entre empresas que comercializam insumos ser maior nesse município, comparativamente aos demais.

Acerca dos preços dos produtos agrícolas comercializados pelos agricultores para a cooperativa, observa-se que os associados de Tapejara e de Caseiros estão mediamente satisfeitos, o que se deve ao fato de que nessas cidades há um índice de concorrência entre empresas compradoras mais elevado, se comparado a outras cidades. Já a satisfação dos associados acerca da qualidade pós-venda da Cooperativa Agrícola X, os números apontam para um índice médio de satisfação para municípios de Coxilha e Caseiros. Acredita-se que o motivo para isso é que a assistência da cooperativa está mais distante dessas cidades, comparativamente às demais, e, com isso, há dificuldade em se fazer um trabalho mais próximo aos associados. Destaca-se, portanto, a necessidade de que a equipe técnica e os vendedores dediquem mais atenção para os associados dessas regiões, que demonstraram maior insatisfação.

A correlação entre localização e satisfação quanto à disposição de informações pela cooperativa para seus associados apontou média de satisfação elevada, exceto em dois municípios, pelo fato de os associados de Coxilha estarem mais distantes da cooperativa e não acompanharem de perto as informações. Já no município de Tapejara, o motivo pode ser por que existe outra cooperativa competitiva e, sendo assim, os associados geralmente participam de ambas e comparam o acesso à informação.

Finalmente, correlaciona-se a localização dos associados com satisfação quanto à sua participação nas ações da Cooperativa Agrícola X. Ficou claro que o município de David Canabarro apresenta 100\% de associados medianamente satisfeitos, isso se deve à forma de atuação da cooperativa, que tem conselheiros e líderes das comunidades em que está estabelecida. Dessa forma, são definidas as lideranças por voto nas reuniões e no município de David Canabarro a unidade ainda não está pronta e, provavelmente por isso, tem menor participação. Já no município de Tapejara, que também apresenta alto percentual de associados medianamente satisfeitos, por que a cooperativa tem unidade de recebimento somente na safra e os associados dessa região tem menor participação nas atividades de cooperativa.

Portanto, a pesquisa também demonstrou que há ainda um trabalho de campo a ser desenvolvido, com ações e decisões que poderão contribuir para melhorar 
a visão do associado em relação à cooperativa, já que falhas na satisfação foram apontadas no resultado da pesquisa. Essas falhas dizem respeito, especialmente, à flexibilidade e rapidez em atender pedidos não programados, às ações de preservação ao meio ambiente e reposição de perdas.

É importante lembrar que algumas comunidades dentro desses municípios estão mais distantes de unidades da cooperativa, o que dificulta o trabalho nos quesitos apresentados. Por fim, alerta-se que esses condicionantes de competitividade precisam ser revistos com os associados para que eles apontem quais as melhores formas para aprimorá-los.

\section{Conclusão}

O objetivo da pesquisa era avaliar os índices de satisfação dos associados quanto aos serviços prestados pela cooperativa bem como compreender a percepção dos associados em relação à gestão, verificando suas políticas de atuação e os sistemas de fidelização em relação ao associado. Conclui-se que, de modo geral, o resultado foi satisfatório do ponto de vista das vantagens competitivas da organização e das ações de fidelização dos associados. Afirma-se isso já que para a maioria dos condicionantes de competitividade analisados, os associados mostraram-se satisfeitos.

A pesquisa permite ainda, ao apontar os condicionantes de competitividade que estão sendo mal trabalhados pela cooperativa, indicar em quais pontos a cooperativa em estudo necessita agir para aumentar a fidelidade dos clientes e melhorar suas vantagens competitivas em relação a outras organizações. Destacam-se como critérios de ação urgente os itens avaliados com baixo índice de satisfação, especialmente, os que dependem diretamente da ação dos dirigentes da cooperativa.

Os critérios com maior nível de insatisfação foram: atendimento no setor financeiro, participação dos associados nas decisões da cooperativa, resposta a pedidos não programados, ações de preservação ambiental. Também com nível importante de insatisfação, mas menor se comparado aos itens mencionados anteriormente, destacam-se: preço dos produtos comercializados pela cooperativa, preço pago pelos produtos vendidos pelos associados para a cooperativa, atendimento pós-venda e prazo de entrega dos produtos.

A organização que objetiva melhorar sua competitividade de mercado utiliza-se de pesquisas como esta para identificar os pontos críticos de ação. Como observado, a presente cooperativa tem como fator essencial de competitividade a satisfação do grupo de associados. Por outro lado, os associados visualizam a Cooperativa Agrícola $\mathrm{X}$, em muitos casos, como mais uma opção de empresa para efetuar transações de compra e venda de produtos e/ou de prestação de serviços. Nesse sentido, a competitividade necessita estar em alta, comparativamente a essas empresas do setor. 


\title{
Management challenges of cooperative: versus loyalty competitiveness
}

\begin{abstract}
The aim of this study was to analyze the level of satisfaction of members about the Agricultural Cooperative X competitiveness constraints as well as to understand the perception of members in relation to the cooperative management by checking the performance of policies the same and systems loyalty by the member. A survey was conducted which involved interviews with a sample of 414 members. As a result, there is a good level of satisfaction of members about the services and products offered by the organization. It stands out as points with lower rates of satisfaction of members: flexibility and speed in meeting requests unscheduled; actions to preserve the environment; replacement losses and services of technical and financial department.
\end{abstract}

Keywords: Agricultural cooperative. Competitiveness. Satisfaction of members.

\section{Retos de gestión de cooperativa: lealtad versus competitividad}

\section{Resumen}

El objetivo de este estudio fue analizar el nivel de satisfacción de los miembros sobre las condiciones de competencia de la Cooperativa Agrícola X, así como para entender la percepción de los miembros con respecto a la gestión cooperativa, comprobando las mismas políticas y sistemas de acción la lealtad por el miembro. La investigación involucró entrevistas con una muestra de 414 miembros. Como resultado, hay un buen nivel de satisfacción de los miembros acerca de los servicios y productos ofrecidos por la organización. Se destaca como puntos con menores índices de satisfacción de los miembros: flexibilidad y velocidad en las convocatorias de reunión no programada; acciones para preservar el medio ambiente; pérdidas de recambio y servicios de oficina técnica y financiera.

Palabras clave: Cooperativa agrícola. Competitividad. Satisfacción de los miembros. 


\section{Referências}

ALIANÇA Cooperativa Internacional. 2011. Disponível em: <http://cooperativismodecredito. coop.br/entidades-de-representacao/aci-alianca-cooperativa-internacional/>. Acesso em: set. 2015.

BRASIL. Lei nº 5.764, de 16 de dezembro de 1971. Define a Política Nacional de Cooperativismo, institui o regime jurídico das sociedades cooperativas, e dá outras providências. Disponível em: <http://www.planalto.gov.br/ccivil_03/LEIS/L5764.htm>. Acesso em: jan. 2015.

C.VALE. Notícias: prêmio para a C.Vale. 2014. Disponível em: <http://www.cvale.com.br/noticia. php?id=1791>. Acesso em: set. 2015.

COOPATOS. Coopatos recebe prêmio Cooperativa do Ano 2014. Disponível em: <http://www. patosemdestaque.com.br/noticias/?n=PSmjXaRv2O >. Acesso em: set. 2015.

GLOBO RURAL. Semana Coopatos arremata prêmio promovido pelo Sistema OCB na categoria fidelização. 2014. Disponível em: <http://revistagloborural.globo.com/Informe-OCB/noticia/2014/12/semana-coopatos-arremata-premio-promovido-pelo-sistema-ocb-na-categoria-fidelizacao.html>. Acesso em: set. 2015.

ORGANIZAÇÃO das Cooperativas do Brasil. 2014. Disponível em: <http://www.sescoop-ro.org. br/2014/page/12/>. Acesso em: out. 2015.

ORGANIZAÇÃO DAS COOPERATIVAS DO BRASIL. Brasil Cooperativo. 2014 Disponível em: <http://www.brasilcooperativo.coop.br/site/agencia_noticias/noticias_detalhes. asp?CodNoticia=17632>. Acesso em: out 2015.

PIVOTO, D. Governança corporativa: uma análise dos problemas oriundos dos direitos de propriedade difusos nas cooperativas agropecuárias do Rio Grande do Sul. 130 p. Dissertação (Mestrado em Agronegócio) - Universidade Federal do Rio Grande do Sul, Porto Alegre, 2013.

VALADARES, J. H. A moderna administração em cooperativas. Rio de Janeiro: Fundação Getúlio Vargas. [201-?]. Apostila cursos in company. Disponível em: <http://www.administracaovirtual.com/administracao/.../Administr_Cooperativas>. Acesso em: ago. 2016. 